\title{
Clusters: Distinctive Features and Implementation Mechanism in the Russian Federation
}

\author{
Yurii Borisovich Mindlin ${ }^{1}$
}

Eugeny Petrovich Kolpak ${ }^{2}$

\section{Natalya Alexandrovna Gasratova²}

\begin{abstract}
${ }^{1}$ PhD of Economic Sciences, Associate Professor, Moscow State University of Mechanical Engineering, Russian Federation, 107023 Moscow, Bolshaya Semenovskaya str., 38 2Saint Petersburg State University, Russian Federation, 199034, Saint Petersburg, Universitetskaya nab., 7/9
\end{abstract}

\author{
Doi:10.5901/mjss.2015.v6n6s3p186
}

\section{Abstract}

Despite the great popularity that clusters have gained both as an object of theoretical inquiry and a practical territorial development instrument, in practice no common opinion can be found as to what entities are to be considered clusters, which leads to problems in formulating regional development strategies based on cluster initiatives. The purpose of this article is to reveal distinctive features of clusters and determine whether those territorial economic entities that are being actively implemented in Russia today may be referred to as clusters. Our analysis work made it possible to ascertain that clusters as networked (hybrid) entities have important distinctive features. The key of which we believe, along with the local base of formation, is to be considered the fact that being comprised of organizations of different types, they do not provide a single mechanism to coordinate interaction. Instead, a wide variety of partnerships are formed, which through interacting with each other become the cluster's basis. Study of the territorial entities originating in Russia shows that they cannot be referred to as clusters, mainly because of the administratively voluntaristic mechanism of their formation.

Keywords: clusters, territorial economic entities, hybrids, networks, territorial development.

\section{Introduction}

The cluster as an instrument of shaping long-term network connections (Menard, 2004) among enterprises and organizations located in the same area has become ever more common over the recent years because, on the one hand, it fosters rapid development of the area in which it is located (through involvement of a large number of enterprises stimulating economic activities, raising employment, improving local demand, and increasing tax-generated income of the local budget), while on the other hand, it makes it possible to make its member organizations function more efficiently (making use of the area's competitive advantages and the integration ties between its members based on a combination of competition and cooperation) (Porter, 1998). This gave rise to a number of publications in which the nature of the cluster was researched as a special form of organizing economic activities on the territorial network basis (starting with Michael Porter's ground-laying work (Porter, 1998), and the cluster implementation practice was analyzed in terms of fostering regional development and improving operational efficiency of its member enterprises (Schmitz \& Nadvi, 1998; McCann, Arita \& Gordon, 2002; Bek et al., 2013 \& Hashino \& Otsuko 2013).

Nevertheless, despite such a considerable array of published works, neither practicians nor theoreticians have ever come to common grounds as to what territorial economic entity may be identified as a cluster. Clusters are often combined with various technoparks, special economic zones, accelerated development regions, etc. This poses difficulties in putting together instruments of managing regional development based on cluster initiatives, obstructs fullscale realization of the cluster's potential as a regional development instrument, and generates pseudo-clusters, i.e. regional economic entities that fail to exhibit the essential features of the cluster (often, through political reasons). This issue is especially severe in Russia, a country with the world's largest territory and yet heavy disproportions on the level of its regional development.

In this research work, we intend to study the cluster's characteristics, attempt to offer a new definition of the cluster basing on the characteristics revealed, and perform a brief analysis whether this definition of ours can be applied to those territorial entities that are now created and actively developed in Russia as clusters.

Above, we made a statement that the cluster is a special territorial networked form of organizing economic activity. 
It would be more appropriate to state that what is meant here is a special form of territorial organization of economic activity based on the network interaction of business entities, government administration agencies, scientific and academic establishments, and public institutions concentrated within a particular region.

All of the above features are equally important for the formation and efficient functioning of a fully shaped cluster.

\section{Methodology and Retrospective Analysis}

A distinctive feature of networked interaction lies in the fact that its member entities abandon the purely market-driven, price signal-based control, yet without going over to the hierarchical administration within an integrated system (Williamson, 1991; Menard, 2004 \& Makadok \& Coff 2009). Formulated by Oliver Williamson (Williamson, 1991; Williamson 1996 \& Williamson, 2008, the network (or hybrid) entity theory has since become subject of many research works, describing different versions of these entities such as outsourcing relations, franchising networks, strategic alliances, and other varieties of inter-firm and inter-organizational alliances (Aldrich, Sasaki, 1995; Arino \& Torre, 1998; Cammet, 2007; Reuer \& Arino, 2007; Gulati \& Nickelson, 2008; Galbraith, 2010; Kotliarov, 2011; Lee, 2011; Gulati, Wohlgezogen \& Zhelyazkov, 2012; Fulmer \& Gelfand, 2012 \& Kotliarov, 2013). As a rule, hybrid entities are comprised of firms.

It is remarkable that, despite the large number of published works devoted to the problems of the hybrid entities, no list of distinctive features was suggested for them. In the important work by Claude Menard devoted, in fact, to the systematization of the available information about hybrids, the independence of members and the long-term partnership duration are suggested as such features, whereas Menard himself points out to their vagueness (Menard, 2004). Therefore, the task of defining characteristic features of the hybrid entities is of great scientific significance and, moreover, it is important for the purposes of our article (because the cluster is a network entity, and we intend to compile a list of the cluster's distinctive features).

The analysis of the existing works makes it possible to maintain that the characteristic features of the hybrid are the following:

1. Combination of hierarchical and market elements in organizing member interaction. It means that in the hybrid, as a rule, a certain central element exists (the local government, according to Claude Menard (Menard, 2004) that partially assumes the authority to coordinate member interaction (which allows to establish uniform cooperation rules and alleviate uncertainty), while the members are not rigidly subordinated to that center (once again, it acts as a coordinator, not a governing company), retain their economic and legal independence, and make decisions aimed at maximizing their profits, and their participation in the partnership does not impose rigid limits to their activities.

2. Combination of cooperation and competition in the hybrid's member interaction. This is a fundamental characteristic, as it opposes networks to pure markets, on the one hand, and pure hierarchies, on the other. Hybrid members cooperate in such matters as those that constitute the area of their common interest (most commonly, when it concerns forming a common pool of assets, both tangible and intangible, and entitling each member to their use), while continuing to compete with each other in those areas where their interests lie apart (usually concerning interaction with end customers).

3. Voluntary entry (Menard, 2004 \& Williamson, 2008). Members form partnerships (or enter into existing hybrids) on their own, aiming for improvement of their operational efficiency. This poses a difference from merger deals, in which the opinion of the merged entity is not taken into account when a merger transaction is settled. In other words, it is the market, and not the administrative mechanism that lays the ground for forming hybrids.

4. Stability of connections (Williamson, 2008). In other words, it is not permanent contracts transacted between the network partners as much as the fact that when a demand arises, providers are sought within the hybrid and not on the open market. This also sets the hybrid apart from the purely market-based interaction.

5. Focus on profit maximization for all members, rather than individual profit of each member. This means that partners are less motivated to seek profits as a result of breaching or circumventing their binding contracts which also sets limits to their behavior because, as a rule, the one-time profit resulting from such a breach/circumvention will fall short of potential losses from being expelled from the hybrid.

6. Strict selection of potential partners (Menard, 2004). Since the relations between hybrid members are not purely hierarchical, it is highly important to have certainty that a partner will deliver on its commitments (Levin \& Cross, 2004; Adobor, 2006 \& Li et al., 2008). This assumes the existence of certain criteria for a potential member to meet and the qualification of members basing on such criteria. The qualification may be quite 
formal or be carried out intuitively, but it is always carried out. Often, the powers required to develop and perform this procedure are delegated to the central coordination element.

The cluster is a networked (hybrid) entity, but it has important distinctive features that determine its specific nature. While such features as combination of cooperation and competition in member interaction and voluntary entry make the cluster no different from other hybrids, other criteria reveal certain differences pertaining to it.

First of all, the cluster is based on the territorial concentration of its members. While in other hybrids partners may be located a long distance from each other (as exampled by outsourcing contracts whose contractors may reside in China, while the customers are in the US or Western Europe), for the cluster territorial proximity is a critical condition of its existence. Accordingly, the soft integration of the cluster's members is secondary - It occurs when there is a sufficient number of enterprises which may produce interconnections, whereas the basic prerequisite of the cluster's formation (i.e. the prerequisite for a certain number of enterprises to be created and successfully function) is the existence of any significant competition advantages pertinent to the region. Such advantages may include (and desirably add up) a region's high resource availability, advanced infrastructure, favorable legislation, or high demand for a certain industry's products. The nature of the resource base and the demand's pattern will determine that basic industry, around which the cluster will begin to form and which, in its turn, will define the cluster's profile. Certainly, the base-industry enterprises within the cluster will be supplemented by the firms of the satellite and supporting industries.

Furthermore, as it was mentioned earlier, hybrids usually consist of commercial firms. Besides firms, clusters include various non-commercial organizations and government or municipal administration agencies. The noncommercial entities (public institutions, academic and scientific establishments) support the cluster's development and serve as a source of skilled workforce and scientific research. As for the administration agencies, they provide legislative support for the cluster initiatives and are responsible for maintaining a favorable legal background for the cluster's activities.

\section{Discussion}

Not all of the cluster's members are involved in a single interaction pattern, as determined by the difference in their purposes and interests (as opposed to, say, outsourcing, franchising, or strategic alliances in which a single interaction mechanism is common to all members (Williamson, 1998; Menard, 2004; Williamson, 2008; Kotliarov, 2011 \& Kotliarov, 2013). Firms would form outsourcing partnerships and strategic alliances, while colleges or universities would interact with the firms through various inter-organizational networks. One way or another, the network interaction additionally involves government and municipal administration agencies. Besides, each member of the cluster may belong to more than one of the above-mentioned partnerships, alliances, or networks which, through intertwining with each other and creating complex interactions (as governed by different types of coordination), mold the basis for the cluster. In its turn, this feature of the cluster causes transformation of the profit maximization and the member selection paradigms. While members of a regular hybrid entity would aim their actions at maximizing their common profits, each member of a cluster would prioritize maximizing profits of that partnership which is considered by that particular member its primary membership (there may be several such partnerships, and in each choice case, profit maximization is prioritized for one of them). In other words, a member of the cluster is also focused on serving the common effort, although not the effort of the entire cluster, but that of a particular community within the cluster. Similarly, there is no common formal member selection procedure in the cluster. Each partnership within the cluster develops and implements its own procedures, and essentially it is possible for a potential member, having failed to join one of the partnerships within the cluster, to be able to join another, thereby still becoming a member of the cluster. Basically, it would suffice to establish a business within the area covered by the cluster, with the business line matching the needs of any particular cluster members, and sooner or later such cluster members will enter into relations with that business. The right to establish a business within the cluster's area is not reserved by anyone (while the nature of such business must certainly meet the legal requirements). Lastly, it is for the same reason that the cluster has no common coordination center. The regional government may assume the role and the function of a soft regulator through various formal and informal motivation measures, however, it does not become a coordination center in the strict sense of the word. 
Table 1 - Comparative analysis of hybrid entities vs. clusters

\begin{tabular}{|c|c|c|}
\hline Comparison criteria & Hybrid entities & Clusters \\
\hline Formation prerequisites & Technological proximity of members & Territorial proximity of members \\
\hline Composition of members & Commercial firms & Commercial and non-commercial entities, government authorities \\
\hline Coordination mechanism & $\begin{array}{l}\text { Combination of market-based and } \\
\text { hierarchical instruments, common to } \\
\text { all members }\end{array}$ & $\begin{array}{l}\text { Cluster members form different types of partnerships, and different } \\
\text { combination forms of market and hierarchical instruments are employed }\end{array}$ \\
\hline $\begin{array}{l}\text { Central governing element } \\
\text { (Local government) }\end{array}$ & Typically present & $\begin{array}{l}\text { Typically absent. Within the cluster, soft coordination is carried out by the } \\
\text { regional authorities through legislative initiatives }\end{array}$ \\
\hline Selection mechanism & Present & $\begin{array}{l}\text { Expressly absent, any business in the area may be involved in the cluster } \\
\text { through one of the cluster's members }\end{array}$ \\
\hline $\begin{array}{l}\text { Maximization of common } \\
\text { vs. private profit }\end{array}$ & Typically present & $\begin{array}{l}\text { Profit maximization for the member's priority partnership instead of the } \\
\text { cluster as a whole }\end{array}$ \\
\hline
\end{tabular}

The analysis of Table 1 makes it possible to maintain that the cluster, as opposed to the hybrid, is not a uniform entity (built upon a single mechanism of coordinating interaction of its members), but a complex structure which is, in fact, a network of hybrids of different kinds - a second-level network, so to say. It is that criterion - being organized on the basis of a networked combination of different networks - that we believe is the system-forming distinctive feature of the cluster, along with its territorial concentration and its mixed membership. That means that the cluster, seemingly a uniformly structured entity for an external observer, is not entirely uniform in its internal structure. This is an important advantage (because it allows its members to select their preferable partners and mechanisms of interaction with them), but at the same time, it makes it more difficult to manage clusters, and because of that spontaneous forces play a considerable role in the functioning of the cluster.

Let us try to analyze the extent to which the territorial development entities that are currently implemented in Russia as clusters match the cluster's distinctive features described above. Having researched the sources available to us (regretfully, mainly in the Russian language), we can state that there are significant differences between those entities and the classical clusters (see Table 2) (Bek et al., 2013).

Table 2 - Comparative analysis of clusters vs. Russian territorial economic entities

\begin{tabular}{|c|c|c|}
\hline Comparison criterion & Cluster & Territorial economic entities in Russia \\
\hline Formation stimulus & $\begin{array}{l}\text { Market-driven (through their initial use of the area's } \\
\text { competitive advantages, enterprises evolve new } \\
\text { interactions to improve their efficiency }\end{array}$ & $\begin{array}{l}\text { Administratively voluntaristic (the decision to create an entity } \\
\text { is made by the federal or regional authorities) }\end{array}$ \\
\hline $\begin{array}{l}\text { Presence of cooperation } \\
\text { and competition }\end{array}$ & Present & $\begin{array}{l}\text { Extremely weak (there is little interaction between enterprises } \\
\text { within a territorial formation) }\end{array}$ \\
\hline Selection mechanism & $\begin{array}{l}\text { Present in each partnership of those existing within the } \\
\text { alliance }\end{array}$ & Absent or enacted by the regional administration \\
\hline Membership & $\begin{array}{l}\text { Commercial entities, scientific and academic } \\
\text { organizations, public institutions, government authorities }\end{array}$ & $\begin{array}{l}\text { Mainly, commercial entities, with a weak presence of } \\
\text { companies from the related and supporting industries. } \\
\text { Membership of scientific and academic organizations is } \\
\text { weak, while the government authorities prefer to exercise } \\
\text { governance of the cluster without being involved too much in } \\
\text { its network interactions }\end{array}$ \\
\hline $\begin{array}{l}\text { Presence of common } \\
\text { governance }\end{array}$ & $\begin{array}{l}\text { No, regional authorities may exercise soft governance } \\
\text { over the cluster through indirect influence actions }\end{array}$ & $\begin{array}{l}\text { Exercised by the government authorities which control the } \\
\text { cluster's activities in a rigid and direct fashion }\end{array}$ \\
\hline
\end{tabular}

Table 2 enables us to maintain that the formations being developed in the Russian Federation are not clusters in the strict sense of the word because they lack such essential distinctive features of the cluster as cooperation and competition, the high level of development of related and supporting industries, and the market-driven formation incentive. By their nature, those territorial formations stand close to sectoral special economic zones or sector-specialized areas. They are characterized by the low level of member interaction and the significant role of the government authorities in development of such entities and management of their activities. Obviously, such a regional development model is valid, too, and may have certain advantages, however, it would be a mistake to call it cluster-based. It involves a totally different implementation mechanism, and application of any cluster-specific management instruments to it will only lead to the inefficient use of resources. 


\section{Research Results}

However, it cannot be argued that this model entirely forbids the use of the cluster paradigm. The point is that such formations are currently in the earliest phases of their development, and now there is still choice which path to follow in their evolution. For Russia with its traditionally high participation of the state in the management of the economic activity, there is certainly a high probability that these formations will further develop along the path of becoming sectorspecialized regions with the state playing an active part in managing their key enterprises. This path may be preferable in terms of preserving the state's option to participate in the management of such territorial economic entities. However, there is a chance for these formations to become protoclusters, in other words, a chance for a transition towards a more market-oriented management paradigm, with the state giving up its manual control, and those firms already operating in that area acting as a seed of the future cluster, also by attracting enterprises from the satellite and supporting industries.

The future will tell exactly which option will be practically implemented. Yet in the present-day economic situation, the approach which would involve transforming these formation into fully shaped clusters seems to be the preferable one, for it will give space to the entrepreneur initiative and release the state from its excessive involvement in the management of the economic activity (i.e., will basically allow to cut its budget expenses).

\section{Conclusion}

To summarize, the following may be stated:

- Clusters as networked hybrids by their nature are more complex formations than regular networks (hybrids). It would be more appropriate to describe them as networks consisting of networked entities (comprised, in their turn, of commercial and non-commercial organizations) and having their territorial connections.

- The territorial economic formations being implemented in the Russian Federation cannot be currently qualified as clusters because they lack essential distinctive features inherent to clusters (in the first place, the networked nature of interaction between its member organizations). Their present-day condition positions them nearest to the special economic zones with sectoral specialization.

- Such territorial economic formations may become protoclusters, subject to a change in the paradigm of their organization on part of the state. Should this change fail to happen, the evolution of these formations will result in establishment of the area with sectoral specialization, but lacking network interaction between its key enterprises.

\section{References}

Adobor, H. (2006). The role of personal relationships in inter-firm alliances: Benefits, dysfunctions, and some suggestions. Business Horizons, 49: 473-486.

Aldrich, H.E. \& Sasaki, T. (1995). R\&D consortia in the United States and Japan. Research Policy, 24: 301-316.

Arino, A. (1998). Learning from failure: Towards an evolutionary model of collaborative ventures. Organization Science, 9: 306-325.

Bek, M.A., Bek, N.N., Sheresheva, M.Y. \& Johnston, W.J. (2013) Perspectives of SME innovation clusters development in Russia, Journal of Business \& Industrial Marketing, 28 (3): $240-259$.

Cammet, M. (2007). Business-Government Relations and Industrial Change: The Politics of Upgrading in Morocco and Tunisia. World Development 35 (11): 1889-1903.

Fulmer, C.A. \& Gelfand, M.J. (2012). At what level (and in whom) we trust: Trust across multiple organizational levels. Journal of Management, 38: 1167-1230.

Galbraith, J. (2010). The multi-dimensional and reconfigurable organization. Organizational Dynamics, 39: 115-125.

Gulati, R. \& Nickerson, J.A. (2008). Interorganizational trust, governance choice, and exchange performance. Organization Science, 19: 688-708.

Gulati, R. \& Wohlgezogen, F. \& Zhelyazkov, P. (2012). The two facets of collaboration: Cooperation and coordination in strategic alliances. Academy of Management Annals, 6: 531-583.

Hashino T. \& Otsuko, K. (2013). Cluster-based industrial development in contemporary developing countries and modern Japanese economic history. Journal of the Japanese and International Economies 30: 19-32.

Kotliarov, I. (2011). Royalty Rate Structure in Case of Franchising. Annals of Economics and Finance 12 (1): 139-156.

Kotliarov, I. (2013). The real price of intellectual property: evaluation of franchisee's benefits. Acta Oeconomica 63 (1): 43-60.

Lee, K.J. (2011). From Interpersonal Networks to Inter-Organizational Alliances for University-Industry Collaborations in Japan: The Case of Tokyo Institute of Technology. R\&D Management 41: 190-201.

Levin, D. Z. \& Cross R. (2004). The Strength of Weak Ties You Can Trust: The Mediating Role of Trust in Effective Knowledge Transfer. Management Science 50: 1477-1490. 
Li, D., Eden, L., Hitt, M.A. \& Ireland, R.D. (2008). Friends, Acquaintances or Strangers? Partner Selection in R\&D Alliances. Academy of Management Journal 51: 315-334.

Makadok, R. \& Coff, R. (2009). Both market and hierarchy: An incentive-system theory of hybrid governance forms. Academy of Management Review, 34: 297-319.

McCann, P., Arita, T. \& Gordon, I.R. (2002). Industrial clusters, transactions costs and the institutional determinants of MNE location behaviour. International Business Review 11 647-663.

Menard, C. (2004). The Economics of Hybrid Organizations. Journal of Institutional and Theoretical Economics 160 (3): $345-376$.

Porter, M.E. (1998). Clusters and the new economics of competition. Harvard Business Review, 76(6), 77-90

Reuer J.J. \& Arino, A. (2007). Strategic Alliance Contract: Dimensions and Determinants of Contractual Complexity. Strategic Management Journal 28 (3): 313-330.

Schmitz, H. \& Nadvi, K. (1999). Clustering and industrialization. World Development, 27(9), 1503-1514.

Williamson, O.E. (1991). Comparative Economic Organization: The Analysis of Discrete Structural Alternatives. Administrative Science Quarterly 36 (2): 269-296.

Williamson, O.E. (1996). The fading boundaries of the firm: Comment by O. E. Williamson. Journal of Institutional and Theoretical Economics 152 (1): 85.88.

Williamson, O.E. (2008). Outsourcing: Transaction Cost Economics and Supply Chain Management. Journal of Supply Chain Management 44 (2): 5-16. 